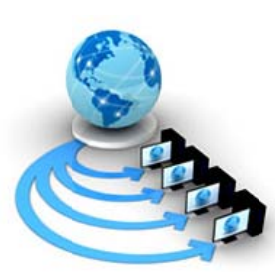

Volume 9, No. 1, January-February 2018

International Journal of Advanced Research in Computer Science

RESEARCH PAPER

\author{
Available Online at www.ijarcs.info
}

\title{
THE INFLUENCE OF TEXT STATISTICS AND READABILITY INDICES ON MEASURING UNIVERSITY WEBSITES
}

\author{
Sukhpuneet Kaur \\ Department of Computer Science \& Engineering, \\ I.K.Gujral Punjab Technical University \\ Kapurthala, India
}

\author{
Dr.Kulwant Kaur \\ School of Information Technology, \\ Apeejay Institute of Management Technical Campus \\ Jalandhar, India
}

\author{
Dr. Parminder Kaur \\ Department of Computer Science \\ Guru Nanak Dev University \\ Amritsar, India
}

\begin{abstract}
In this competitive world, websites are considered to be key trait of any organization's effectiveness. An Institution website is a gateway to its statistics, products and services. The usability is very important feature of individual website to existence in digital setting for each institution. The different factors to measure Usability are Readability, Navigation, Structure, Organization and Content, Search and Retrieval, and Satisfaction. But in previous research to measure the website built on Readability aspect and the average grade of country grading system based on readability indices was somewhere missing. To address this issue, the aim of this paper is to evaluate the Readability indices and Text statistics of twenty-four websites of universities in Punjab. The Readability content of the websites' is measured with six diverse indices such as, Flesch Reading Ease formula, Flesch Kincaid Grade Level Index, Gunning Fog Index, SMOG, Coleman Liau and Automated Readability Index and finally concluded with the analysis of websites against their readability indices.
\end{abstract}

Keywords:readability; readability indices; grade; usability; ranking; complexity; quality; ranking

\section{INTRODUCTION}

The World Wide Web (WWW) has turn out to be acrucial tool for information consumption. The web developers have long been worried about the language complexity and its influence on data quality. To measure the readability of website to produce the web search result ranking is a major concern in this paper. Some readability metrics have been engaged to evaluate the usability of websites [1].Readability marks the quality of printed text easy or hard to read and understand. The handling of data provides information and the information is beneficial only when we can make intellect of it. For the reason that, readability examination for web pages turn into a vital task to sort the contents easily consumed by severaltypes of users [2]. When the content is readable, it's easier to consume. If usability and UX(User eXperience) is important, then readability should be a top priority.

The overall goal of this paper is to find the readability status of twenty-four websites of Universities in Punjabby using Readability evaluation tools.

The rest of the paper is arranged as follows: The related work is presented in Section 2, with particularly focus on the readability metrics to evaluate the website's text, Section 3introduces the readability formulae's to evaluate the readability of website's content.Section 4, presented the results of readability factor for various universities of Punjab.Section 5 concludes the paper with a viewpoint at future work.

\section{RELATED WORK}

The readability of websites is taken as major consideration in this paper. An evaluation of Universities of Punjab is evaluated. This section listed a number ofstudies significant to this paper.

Misra et al.(2013)used the standard readability formulas in diverse fields like industry, training, engineering, military etc. Researchers have accomplished the readability valuation of 17 health care-oriented tutoring resources by using Readability Studio Professional (version 2012.1) tool [3].

Yamasaki et al. (2014) finalized the cross validation experiment to catch the performance of readability scheme for web document [4].

Kumar et al. (2016) considered the readability metrics from patient education materials (PEM) withTextStat 0.1 .4 textual analysis package for Python 2.7 [5].

Collin et al. (2014) implemented the assessment on Computational evaluation of text readability to foretell the text difficulty and innovativetask and opportunities' for upcoming investigation were also prepared [6].

Sato et al. (2008) used the technique of readability in Japanese writings to measure the performance of correlation coefficient built on textbook [7].

Kauchak et al. (2016) work was showed to inspect the current readability formulas and support to design operational text simplification software related to health [8]. Dubay (2008) presented the essentialtheoriesaround readability and the procedure used to check readability in his book entitled "Smart Language". This volume also refer to 
the computational method and arranging of texts on the basis of readability score [9].

\section{READABILITY DEFINITIONS}

According to Edgar Dale and Jeanne Chall (1949) [10], "Readability is the amountof all those elements inside a given piece of printed material that marks the success, which a set of readers have with it. The success is the degree to which they comprehend it, read it at thebest speed, and find it interesting"[9]. Alternative definition is given by George Klare (1963) that "the easiness of understanding or comprehension due to the style of Writing" [9]. Gretchen Hargis and her Colleagues at IBM (1998) state that Readability is defined as the "simplicity of reading words and sentences”[9]. Harry McLaughlin (1969) [13]- the creator of SMOG readability formula [9] defines the readability as "the degree to which a certaincourse of individuals find assured reading material compelling and understandable." So, this definition emphases the collaborationconcerning the text and the readers of recognized levels of skill, knowledge, and interest. There are two suppliersspecifically the reader and the text, too easy reading. The structurescompriseearlierdata, reading ability, concern, encouragement, satisfied, style, enterprise, and organization etc., of the script that marks reading easy. So, Readability is the simplicity of reading in relations of above types.

\subsection{Readability Formulae}

A readability index is anamount to direct the density of written text. Comparatively often they are concentrated on simple features, for instance sentence and word length, and identify how easy it is to read and figure out a text. There are many readability formulas which are used for determining the readability of content.

\section{Flesch Kincaid Reading Ease}

(FKRE):TheFleschKincaid Reading Ease (FKRE) index [8] is aextendedrecognized index in this framework. The score of FKRE typically ranges amongst 0 and 100. A higher score designates a text that is easier to read and understand. Low scores recommend the text is complicated to comprehend. The Flesch Kincaid Reading Ease is defined as:

$$
\begin{aligned}
& 206.835-1.015 \times\left(\frac{\text { numberofwords }}{\text { numberofsentences }}\right)-84.6 \times \\
& \left(\frac{\text { numberof syllables }}{\text { numberofwords }}\right)
\end{aligned}
$$

A syllable is the sound of a vowel (A, E, I, O, U) that is created when pronouncing the letters A, E, I, O, U, or Y and sentences is a combination of words.

A value between 60 and 80 should be easy for a 12 to 15 year old to understand.The overall summary of Understanding status of script by Flesch Kincaid Readability Ease (FKR) formula is shown in Table 1.
Table 1: Status of Readability Score of FKRE [8]

\begin{tabular}{|l|l|}
\hline \multicolumn{1}{|c|}{ Readability Score } & Status \\
\hline $90-100$ & Very Easy \\
\hline $80-90$ & Easy \\
\hline $70-80$ & Fairly Easy \\
\hline $60-70$ & Normal \\
\hline $50-60$ & Fairly Difficult \\
\hline $30-50$ & Difficult \\
\hline $0-30$ & Very Difficult \\
\hline
\end{tabular}

2. Flesch Kincaid Grade Level (FKG): This readability indexassociates the readability of the text to the US schools grade.The FKG is defined as:

$0.39 \times\left(\frac{\text { numberofwords }}{\text { numberofsentences }}\right)+11.8 \times\left(\frac{\text { numberof syllables }}{\text { numberofwords }}\right)-$ 15.59

This formula is reorganized version of Flesch Reading Ease formula and is commonly used in the area of education. The Defence department of US Government uses this formula as a standard test.

3. Gunning Fog Score (GF Score): It is also called Fog Index and is similar to Flesch scale. The best score of this index is 7 or 8 and whatsoever above 12 is moreover hard to read. That is, in over-all, score 5 is readable, 10 is hard, 15 is difficult and 20 is very difficult to understand the text. The Gunning fog index is defined as:

$$
\begin{array}{r}
0.4 \times\left(\left(\frac{\text { numberofwords }}{\text { numberofsentences }}\right)+100\right. \\
\left.\times\left(\frac{\text { numberof complexwords }}{\text { numberofwords }}\right)\right)
\end{array}
$$

The original Gunning fog formula was built on clauses and not on the total of sentences. This rendered the Gunning fog too challenging to be calculated automatically. Thus, the formulation offeredin equation (3) is largelysuggested.

4. SMOG Index:The SMOG is an acronym for Simple Measure of Gobbledygook3 and its formulation is measured suitable for secondary age students that is, 4th grade to college level readers.McLaughlin [13] presented a different factor in his readability formula: the amount of polysyllables. A polysyllable is a term made of three or further syllables. The SMOG grading index is well-defined as:

$$
1.0430 \times \sqrt{\frac{30 \times \text { complexwords }}{\text { sentences }}}+3.1291
$$

5. Coleman Liau Index: It is constructed on characters instead of syllables per word and sentence length. It also practices US grade based formula to recognize the text. The Coleman Liau Index is defined as:

$5.89 \times\left(\frac{\text { no.ofcharacters }}{\text { no.ofwords }}\right)-0.3 \times\left(\frac{\text { no.ofsentences }}{\text { no.ofwords }}\right)-15.8$

6. Automated Readability Index (ARI):It is derived from the fractions representing word difficultly and 
sentence difficultly. The Automated Readability Index is defined as:

$$
4.71 \times\left(\frac{\text { no.ofcharacters }}{\text { no.ofwords }}\right)+0.5 \times\left(\frac{\text { no.ofwords }}{\text { no.ofsentences }}\right)-21.43
$$

ARIprovides number as output that estimates the age required to understand or comprehend the text and is furthermorecentered on US grading level system as shown in Table 2.

Table 2: Grade Levelvs Age

\begin{tabular}{|l|l|}
\hline \multicolumn{1}{|c|}{ Age } & \multicolumn{1}{c|}{ Grade } \\
\hline $5-6$ old & Kindergarten \\
\hline $6-7$ old & First \\
\hline $7-8$ old & Second \\
\hline $8-9$ old & Third \\
\hline $9-10$ old & Fourth \\
\hline $10-11$ old & Fifth \\
\hline $11-12$ old & Sixth \\
\hline $12-13$ old & Seventh \\
\hline $13-14$ old & Eighth \\
\hline $14-15$ old & Ninth \\
\hline $15-16$ old & Ten \\
\hline $16-17$ old & Eleven \\
\hline $17-18$ old & Twelvth \\
\hline $18-22$ old & College \\
\hline
\end{tabular}

Coleman Liau and ARI rely on counting characters, words and sentence. The other indices consider number of syllables and complex words. These all Readability formulas involve two measurable aspects of a text such as, word length and sentence length and a weighted combination of both aspects.
There are numerous online Readability score calculation tools available. Designed for analysis, in this paper, the subsequent methods which are established on the collection of readability score calculation tools are used.

1. Online-Utility.org: It is a group of free readability score calculation tool. The tool is based on four methods of readability in terms of US grade level to understand the text,these are involved Coleman Liau index, Flesh Kincaid Grade level, ARI (Automated Readability Index) and SMOG (Simple Measure of Gobbledygook). This online-utility.org (OnlineUtility) also consist of Gunning Fog Index that offers the sign of the number of years of formal education that a person needs in order to easily understand the text on the first reading. It also shows the recommendations of complex sentences in order to do enhancement in readability.

2. Readability Test Tool: This tool (Webpagefx) is accessible online to check the readability of web pages by three dissimilarways specifically Test by URL, Test by Direct Input or Test by Referrer. To perform analysis on websites, we use Test by URL method for twentyfour websites of Universities in Punjab to measure the readability estimation score by different readability indices techniques.

In this research work, Readability Test Tool using Webpagefxtoolis opted which covers six readability measures to evaluate the website whereas Online-Utility.org covers only four measures of readability.The Universities of Punjab websites which are evaluated to measure the readability is listed in Table 3 and Collection of URL of the website and passed it into a Webpagefx Tool snapshot is shown in Figure 1.

\section{READABILITY TOOL ANDANALYSIS OF WEBSITES}

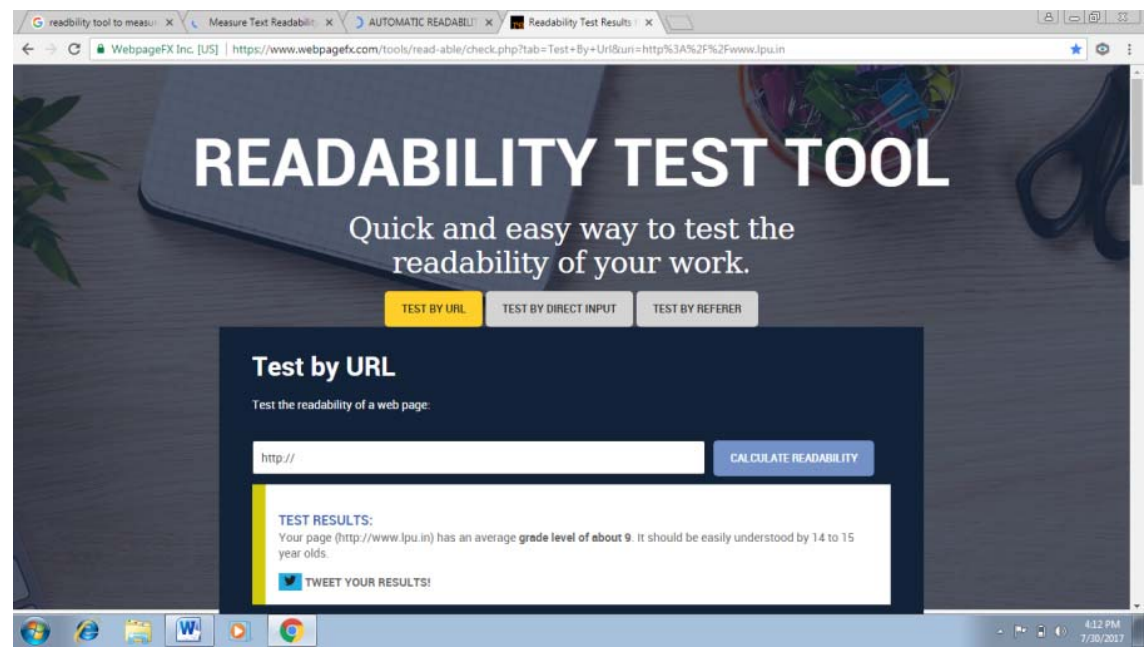

Figure 1: Snapshot of Webpagefx Tool 
Table 3: List of Twenty-four websites of Universities in Punjab

\begin{tabular}{|c|c|c|c|}
\hline S.No. & URLs & Name of Website & Symbol \\
\hline 1. & www.ptu.ac.in & I.K.Gujral Punjab Technical University, Kapurthala & U1 \\
\hline 2. & www.lpu.in & Lovely Professional University, Phagwara & $\mathrm{U} 2$ \\
\hline 3. & www.punjabiuniversity.ac.in & Punjabi University, Patiala & U3 \\
\hline 4. & www.thapar.edu & Thapar Institute of Engineering and Technology, Patiala & $\mathrm{U} 4$ \\
\hline 5. & www.cup.ac.in & Central University of Punjab, Bathinda & U5 \\
\hline 6. & www.sliet.ac.in & SantLongowal Institute of Engineering and Technology, Sangrur & U6 \\
\hline 7. & www.davuniversity.org & DAV University,Jalandhar & U7 \\
\hline 8. & www.pau.edu & Punjab Agriculture University, Ludhiana & U8 \\
\hline 9. & www.iitrpr.ac.in & Indian Institute of TechnologyRopar & U9 \\
\hline 10. & www.puchd.ac.in & Punjab University, Chandigarh & U10 \\
\hline 11. & www.bfuhs.ac.in & Baba Farid University of Health Sciences, Faridkot & U11 \\
\hline 12. & www.gadvasu.in & $\begin{array}{l}\text { Guru AngadDev Veterinary \& Animal Sciences University, } \\
\text { Ludhiana }\end{array}$ & U12 \\
\hline 13. & www.pec.ac.in & PEC University, Chandigarh & U13 \\
\hline 14. & www.ctuniversity.in & C.T.University, Jalandhar & U14 \\
\hline 15. & www.gurukashi.in & Guru Kashi University, Talwandi Sabo, Bathinda & U15 \\
\hline 16. & www.auts.ac.in & Akal University Talwandi Sabo, Bathinda & U16 \\
\hline 17. & www.gnauniversity.edu.in & GNA University, Phagwara & U17 \\
\hline 18. & www.mrsphr.ac.in & Maharaja Ranjit Singh Punjab Technical University, Bathinda & U18 \\
\hline 19. & www.chitkara.edu.in & Chitkara University, Chandigarh & U19 \\
\hline 20. & www.rimt.ac.in & RIMT, MandiGobindgarh & $\mathrm{U} 20$ \\
\hline 21. & www.rayatbahra.edu.in & RayatBahra University, Kharar & $\mathrm{U} 21$ \\
\hline 22. & www.iimamritsar.ac.in & IIM, Amritsar & $\mathrm{U} 22$ \\
\hline 23. & www.adeshuniversity.ac.in & Adesh University, Bathinda & $\mathrm{U} 23$ \\
\hline 24. & www.gndu.ac.in & Guru Nanak Dev University, Amritsar & $\mathrm{U} 24$ \\
\hline
\end{tabular}

The procedure of readability test tool (Webpagefx) [14] contains the resulting steps:

1. Pass URL of the website in a given tool and then start the method of testing.

2. Testing total amount of sentences, words, complex words, the percentage of complex words, average words per sentence, and average syllables per word.

3 . At that point, testing comprises the subsequent metrics to calculate the readability score separately.

- $\quad$ Flesh Kincaid Reading Ease

- $\quad$ Flesh Kincaid Grade Level

- Gunning Fog Score

- $\quad$ SMOG Index
- $\quad$ Coleman Liau Index

- $\quad$ Automated Readability Index

4. Based on step 2 and 3, average grade level and a sum of years from the past to apprehend the text of the web pages as per US Grade system, is obtained.

The Webpagefx tool calculates Readability indices and Text statistics of website.

4.1 Readability indices: The estimation report of readability indices method is displayed in Table 4 which is used for twenty-four University websites of Punjab to check their readability estimation score.

Table 4: Readability indices of Twenty-four websites of Universities in Punjab

\begin{tabular}{|c|c|c|c|c|c|c|c|}
\hline S.No. & URLs & FKRE & FKG & GF & SMOG & CL & AR \\
\hline U1 & www.ptu.ac.in & 45 & 9.5 & 6.6 & 8.7 & 12.3 & 6.1 \\
\hline U2 & www.lpu.in & 49.3 & 8.1 & 6.8 & 7.1 & 15 & 6.6 \\
\hline $\mathrm{U3}^{*}$ & www.punjabiuniversity.ac.in & 121.2 & -3.4 & 0.4 & 1.8 & -16.1 & -20.9 \\
\hline U4 & www.thapar.edu & 23.7 & 11 & 7.3 & 6.9 & 19.3 & 8.8 \\
\hline U5 ${ }^{*}$ & www.cup.ac.in & 121.2 & -3.4 & 0.4 & 1.8 & -16.1 & -20.9 \\
\hline U6 & www.sliet.ac.in & 40.1 & 8.5 & 4.1 & 5.8 & 15.4 & 5.3 \\
\hline U7 & www.davuniversity.org & 43.7 & 8 & 5.6 & 5.7 & 13.3 & 3.6 \\
\hline U8 & www.pau.edu & 47.4 & 8 & 3.9 & 6.8 & 11.8 & 3.4 \\
\hline U9 & www.iitrpr.ac.in & 15.8 & 11.8 & 7.4 & 6.1 & 21.6 & 10 \\
\hline U10 & www.puchd.ac.in & 40.8 & 8.9 & 5.9 & 6.9 & 14.3 & 5.3 \\
\hline U11* & www.bfuhs.ac.in & 18.4 & 15.4 & 7.6 & 11.6 & 20.5 & 17.1 \\
\hline U12 & www.gadvasu.in & 43.5 & 8.7 & 5.2 & 7.7 & 14.1 & 5.6 \\
\hline U13 & www.pec.ac.in & 18.3 & 11.8 & 6.5 & 7 & 21.3 & 10.5 \\
\hline U14 & www.ctuniversity.in & 50.2 & 7.6 & 6.2 & 6.4 & 15 & 5.9 \\
\hline
\end{tabular}




\begin{tabular}{|llcccccc|}
\hline U15 $^{*}$ & www.gurukashiuniversity.in & 77.9 & 2.9 & 0.8 & 1.8 & 6.1 & -2.8 \\
\hline U16 & www.auts.ac.in & 37.4 & 8.7 & 7.1 & 5.5 & 15.9 & 5.4 \\
\hline U17 & www.gnauniversity.edu.in & 38.1 & 9.4 & 7.7 & 7.5 & 15.9 & 7 \\
\hline U18 & www.mrsphr.ac.in & 36.5 & 11 & 7.1 & 10.1 & 14.7 & 8.7 \\
\hline U19 & www.chitkara.edu.in & 34.1 & 9.7 & 5.7 & 7 & 16.2 & 6.6 \\
\hline U20 & www.rimt.ac.in & 36.3 & 9.8 & 8.5 & 7.8 & 17 & 8.1 \\
\hline U21 & www.rayatbahra.edu.in & 36.8 & 9 & 7.4 & 5.8 & 16.8 & 6.5 \\
\hline U22 & www.iimamritsar.ac.in & 49.2 & 7.8 & 5.1 & 7 & 13.3 & 4.6 \\
\hline U23 & www.adeshuniversity.ac.in & 22.2 & 10.8 & 3.8 & 5.5 & 21.1 & 9.5 \\
\hline U24 & www.web.gndu.ac.in & 42.8 & 8.4 & 5.4 & 6.2 & 15.4 & 5.8 \\
\hline
\end{tabular}

${ }^{x}$ means regional fonts are used in website

4.2 Text Statistics:This statistics is responsible forcomprehensive information about the text inside the websites which were evaluated by using different indices in terms of their readability to find a number of sentences, words, complex words, and percent of complex words, average words per sentences and average syllables per word.
Also, there are some indices like Coleman Liau and Automated Readability Index (ARI) built on counting the characters, words and sentences, and some other based on a number of syllables and complex words. The general text statistics of twenty-four websites of Universities in Punjab are shown in Table 5.

Table 5: Text Statistics of Twenty-fourwebsites of Universities of Punjab

\begin{tabular}{|c|c|c|c|c|c|c|c|}
\hline S.No. & URLs & $\begin{array}{l}\text { No. of } \\
\text { sentences }\end{array}$ & $\begin{array}{l}\text { No. of } \\
\text { words }\end{array}$ & $\begin{array}{l}\text { No. of } \\
\text { complex } \\
\text { words }\end{array}$ & $\begin{array}{l}\% \text { of } \\
\text { complex } \\
\text { words }\end{array}$ & $\begin{array}{l}\text { Average } \\
\text { words/sen } \\
\text { tences }\end{array}$ & $\begin{array}{l}\text { Average } \\
\text { syllables/w } \\
\text { ords }\end{array}$ \\
\hline U1 & www.ptu.ac.in & 125 & 1056 & 214 & 20.27 & 10.15 & 1.76 \\
\hline U2 & www.lpu.in & 532 & 2950 & 569 & 19.29 & 6.83 & 1.75 \\
\hline $\mathbf{U}^{\mathbf{x}}$ & www.punjabiuniversity.ac.in & 1 & 1 & 0 & 0 & 1 & 1 \\
\hline U4 & www.thapar.edu & 181 & 643 & 160 & 24.88 & 4.29 & 1.98 \\
\hline $\mathbf{U} 5^{\mathbf{x}}$ & www.cup.ac.in & 1 & 1 & 0 & 0 & 1 & 1 \\
\hline U6 & www.sliet.ac.in & 156 & 461 & 108 & 23.43 & 3.38 & 1.87 \\
\hline U7 & www.davuniversity.org & 318 & 1049 & 277 & 26.41 & 3.35 & 1.89 \\
\hline U8 & www.pau.edu & 202 & 1012 & 227 & 22.43 & 5.45 & 1.79 \\
\hline U9 & www.iitrpr.ac.in & 95 & 267 & 97 & 36.33 & 2.87 & 2.22 \\
\hline U10 & www.puchd.ac.in & 100 & 522 & 129 & 24.71 & 5.40 & 1.89 \\
\hline $\mathrm{U11}^{\mathrm{x}}$ & www.bfuhs.ac.in & 1 & 19 & 4 & 21.05 & 19 & 2 \\
\hline U12 & www.gadvasu.in & 368 & 2042 & 506 & 24.78 & 6.18 & 1.80 \\
\hline U13 & www.pec.ac.in & 153 & 605 & 182 & 30.08 & 4.37 & 2.13 \\
\hline U14 & www.ctuniversity.in & 134 & 698 & 154 & 22.06 & 5.21 & 1.79 \\
\hline $\mathrm{U}^{1} 5^{\mathrm{x}}$ & www.gurukashiuniversity.in & 2 & 4 & 0 & 0 & 2.0 & 1.50 \\
\hline U16 & www.auts.ac.in & 460 & 1036 & 235 & 22.68 & 2.76 & 1.87 \\
\hline U17 & www.gnauniversity.edu.in & 337 & 1748 & 441 & 25.23 & 6.06 & 1.91 \\
\hline U18 & www.mrsphr.ac.in & 238 & 2653 & 697 & 26.27 & 11.50 & 1.87 \\
\hline U19 & www.chitkara.edu.in & 617 & 2346 & 552 & 23.52 & 4.84 & 1.89 \\
\hline U20 & www.rimt.ac.in & 195 & 1239 & 335 & 27.04 & 6.49 & 1.94 \\
\hline U21 & www.rayatbahra.edu.in & 274 & 979 & 253 & 25.84 & 3.57 & 1.97 \\
\hline U22 & www.iimamritsar.ac.in & 60 & 331 & 85 & 25.68 & 5.52 & 1.80 \\
\hline U23 & www.adeshuniversity.ac.in & 53 & 113 & 31 & 27.43 & 2.54 & 2.13 \\
\hline U24 & www.web.gndu.ac.in & 321 & 1412 & 347 & 24.58 & 4.40 & 1.89 \\
\hline
\end{tabular}

${ }^{\mathrm{x}}$ means regional fonts are used in website

From tables Table 4 and Table 5, the average and no. of agesto understand the text of web pages as per US Grade system is shown in Table 6. 
Table 6: Average Grade Level Test Results of 24 Websites of Universities of Punjab

\begin{tabular}{|llcc|} 
S.No. & \multicolumn{1}{c}{ URLs } & Average Grade Level & $\begin{array}{c}\text { No. of Years old to easily } \\
\text { understand }\end{array}$ \\
\hline U1 & www.ptu.ac.in & 9 & 14 to 15 \\
\hline U2 & www.lpu.in & 9 & 14 to 15 \\
\hline U3 & www.punjabiuniversity.ac.in & -8 & -3 to -2 \\
\hline U4 & www.thapar.edu & 11 & 16 to 17 \\
\hline U5 $^{*}$ & www.cup.ac.in & -8 & -3 to -2 \\
\hline U6 & www.sliet.ac.in & 8 & 13 to 14 \\
\hline U7 & www.davuniversity.org & 7 & 12 to 13 \\
\hline U8 & www.pau.edu & 7 & 12 to 13 \\
\hline U9 & www.iitrpr.ac.in & 11 & 16 to 17 \\
\hline U10 & www.puchd.ac.in & 8 & 13 to 14 \\
\hline U11 & www.bfuhs.ac.in & 14 & 19 to 2 \\
\hline U12 & www.gadvasu.in & 8 & 13 to 14 \\
\hline U13 & www.pec.ac.in & 11 & 16 to 17 \\
\hline U14 & www.ctuniversity.in & 8 & 13 to 14 \\
\hline U15 & www.gurukashiuniversity.in & 2 & 07 to 08 \\
\hline U16 & www.auts.ac.in & 9 & 14 to 15 \\
\hline U17 & www.gnauniversity.edu.in & 10 & 15 to 16 \\
\hline U18 & www.mrsphr.ac.in & 10 & 15 to 16 \\
\hline U19 & www.chitkara.edu.in & 9 & 14 to 15 \\
\hline U20 & www.rimt.ac.in & 10 & 15 to 16 \\
\hline U21 & www.rayatbahra.edu.in & 9 & 14 to 15 \\
\hline U22 & www.iimamritsar.ac.in & 8 & 13 to 14 \\
\hline U23 & www.adeshuniversity.ac.in & 10 & 15 to 16 \\
\hline U24 & www.web.gndu.ac.in & 8 & 13 to 14 \\
\hline ww & & \\
\hline
\end{tabular}

${ }^{x}$ means regional fonts are used in website

The Graphical representation of 24 websites of Universities in Punjab by using Flesch Kincaid Reading ease, Flesh
Kincaid Grade, Gunning Fog, SMOG, CL and ARI is shown in Figure 2.

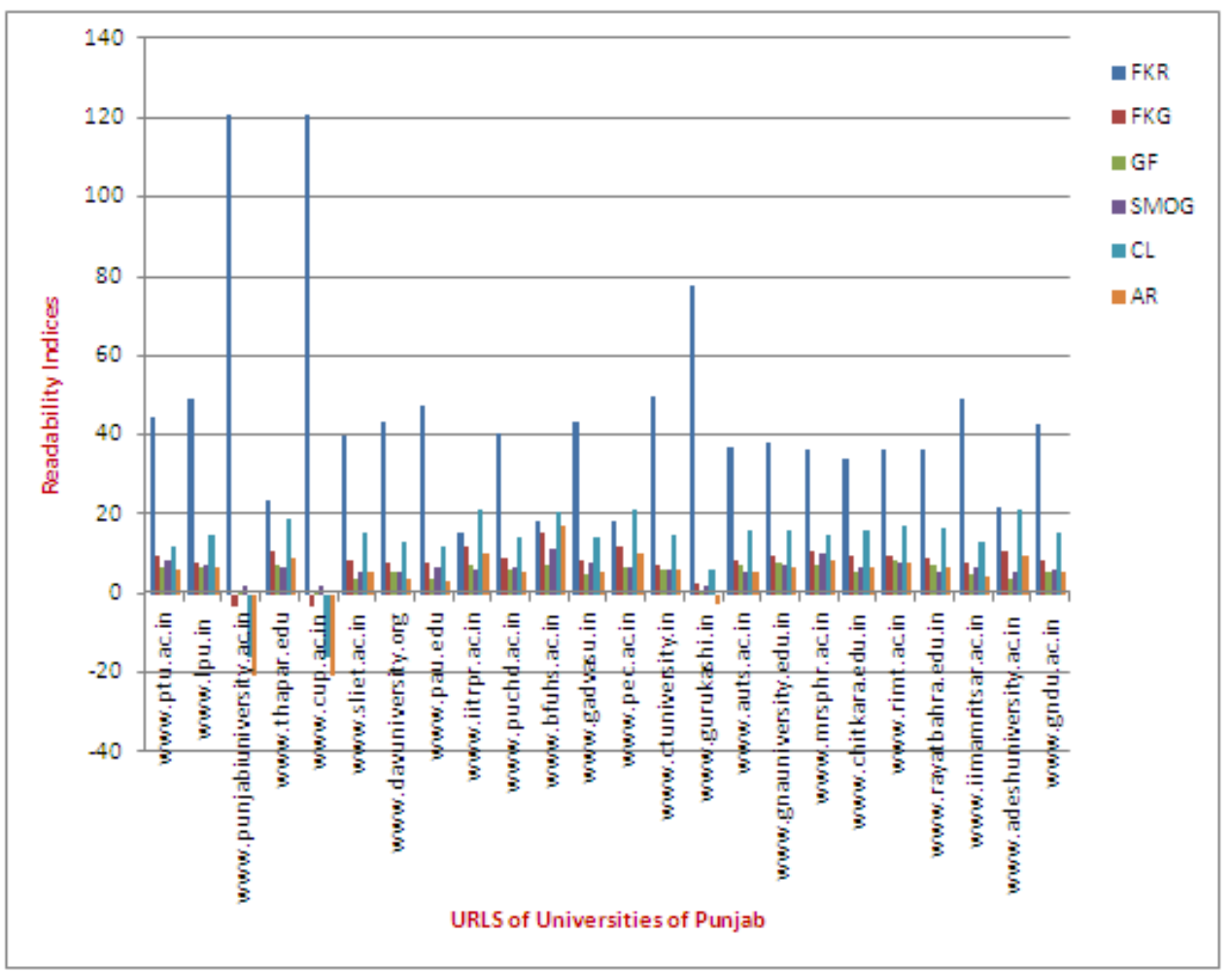

Figure 2: Representation of Readability indices of 24 University websites of Punjab 
Interpretation: FKRE is high in U3 (121.2) i.e. Punjabi University, Patiala and U5 (121.2) i.e. Central University of Punjab, Bathinda but these websites are using regional fonts. As per US based grading system, Webpagefx tool is not considering regional fonts. So we have to skip the FKRE values of U3,U5, U11 and U15. Higher the value of FKRE indicates a text is easier to read and understand. From the results of Webpagefx tool, FKRE is high in U14 (www.ctuniversity.in), U2 (www.lpu.in) and U22 (www.iimamritsar.ac.in). FKG is high in U13(www.pec.ac.in), U9 (www.iitrpr.ac.in) and U1 (www.ptu.ac.in). For evaluating GF, ideal score is 7 or 8 and anything above is hard to read. The analysis was carried out from September to December, 2017 for measuring the readability indices of twenty-four websites of Universities in Punjab. Table 7 shows the analysis of website's against their readability indices. For SMOG and ARI indices, the ideal score is 7.

Table 7: Analysis of Readability indices of websites carried out from September to December, 2017

\begin{tabular}{|l|c|c|c|}
\hline \multicolumn{1}{|c|}{ Readability indices } & Sept-Oct & Oct-Nov & Nov-Dec \\
\hline FKRE & U14 & U14,U2 & U14,U2 \\
\hline FKG & U9, U13 & U18 & U18 \\
\hline GF & U16 & U9 & U16 \\
\hline SMOG & U13,U19,U22 & U19,U22 & U19,U22 \\
\hline CL & U2 & U2 & U2 \\
\hline ARI & U17 & U17 & U17 \\
\hline
\end{tabular}

(U2:www.lpu.in, U9:www.iitrpr.ac.in, U13: www.pec.ac.in, U14: www.ctuniversity.in, U16: www.auts.ac.in, U17:www.gnauniversity.edu.in,U18: www.mrsphr.ac.in, U19: www.chitkara.edu.in, U22: www.iimamritsar.ac.in)

\section{CONCLUSION AND FUTURE WORK}

This paper has presented an analysis of twenty-four websites of Universities of Punjab based on six readability measurement techniques. The analysis was carried out with the help of readability tool (Webpagefx) [14]. The data collection was performed between September, 2017 to December 2017. As per the scores were based on US based grading system, there is a solid need to improve country based particular grading mechanism with respect to readability. If text is too complicated and hard to understand, people will leave that webpage. On the other hand, if text scores a very low grade level, users will likely assume that content of webpage isn't valuable. In order to maximize the readability, it's important for the content of website to reflect the readability expectations of visitors.

The average grade levels of these websites are represented in Figure 3. The Readability indices and Text statistics are measured with respect to different days to check whether it will affect University website grading or not. These measurements are shown in appendix Table A1, A2, A3, Table B1, B2 , B3 and Table C1, C2 and C3.

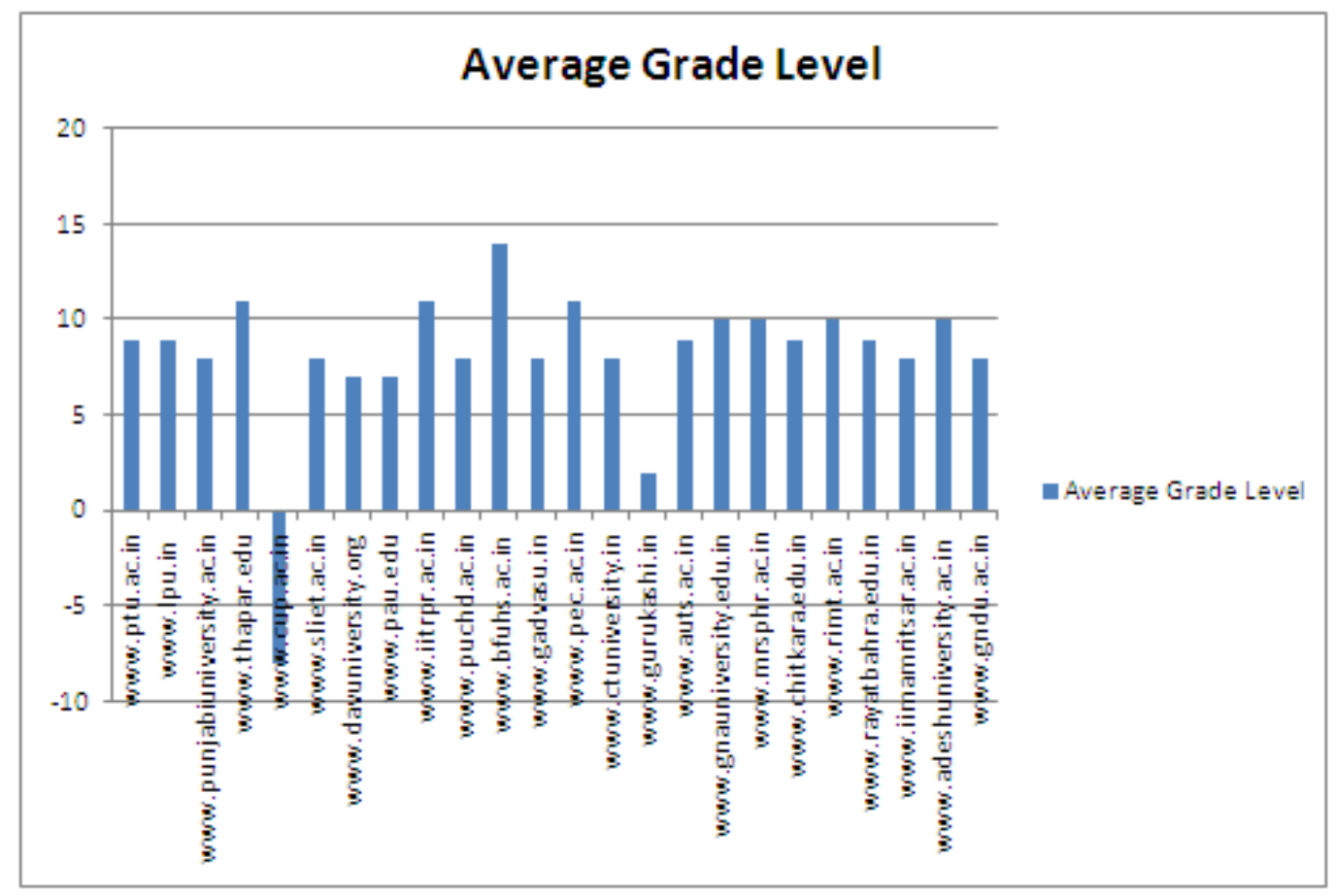

Figure 3: Average Grade Level 
The complete readability score of these websites are not too good so there is a need for additional improvements. The main limitation of Webpagefx tool is that it does not recognize regional fonts of website, even though this tool works only on US based grading system. In order to appeal to target audience, text needs to meet their readability expectations. The main thing is to consider that whether the websites are for children or for adult readers? Understanding the readability expectations of target audience will help to keep people to remain websites for longer period of time, and increase engagement with website content.

\section{REFERENCES}

1. Fulcher, G. (1997). Text difficulty and accessibility: Reading formulae and expert judgement. System, 25(4), 497-513.

2. Kienle, H. M., \&Vasiliu, C. A. (2008, October). Evolution of legal statements on the web. In Web Site Evolution, 2008. WSE 2008. 10th International Symposium on (pp. 73-82). IEEE.

3. Misra, P., Agarwal, N., Kasabwala, K., Hansberry, D. R., Setzen, M., \&Eloy, J. A. (2013). Readability analysis of healthcare-oriented education resources from the american academy of facial plastic and reconstructive surgery. The Laryngoscope, 123(1), 90-96.

4. Yamasaki, T., \&Tokiwa, K. I. (2014). A method of readability assessment for web documents using text features and html structures. Electronics and Communications in Japan, 97(10), 1-10.

5. Kumar, G., Howard, S. K., Kou, A., Kim, T. E., Butwick, A. J., \& Mariano, E. R. (2016). Availability and readability of online patient education materials regarding regional anesthesia techniques for perioperative pain management. Pain Medicine, pnw179.

6. Collins-Thompson, K. (2014). Computational assessment of text readability: A survey of current and future research. ITL-International Journal of Applied Linguistics, 165(2), 97-135.

7. Sato, S., Matsuyoshi, S., \&Kondoh, Y. (2008, May). Automatic Assessment of Japanese Text Readability Based on a Textbook Corpus. In LREC.

8. Kauchak, D., \& Leroy, G. (2016). Moving beyond readability metrics for health-related text simplification. IT professional, 18(3), 45-51.

9. DuBay, W. H. (2007). Smart Language: Readers, Readability, and the Grading of Text.

10. Dale, E., \&Chall, J. S. (1949). The concept of readability. Elementary English, 26(1), 19-26.

11. Klare, G. R. (1988). The formative years. Readability: Its past, present, and future, 14-34.

12. Flesch, R. (1948). A new readability yardstick. Journal of applied psychology, 32(3), 221.

13. Mc Laughlin, G. H. (1969). SMOG grading-a new readability formula. Journal of reading, 12(8), 639-646.

14. https://www.webpagefx.com/tools/read-able/check.php? (accessed on 12 July 2017)

\section{APPENDIX}

Table A1:Readability Indices(30/9/2017)

\begin{tabular}{|llcccccc|}
\hline S.No. & \multicolumn{1}{c}{ URLs } & FKR & FKG & GF & SMOG & CL & AR \\
\hline U1 & www.ptu.ac.in & 39.5 & 11 & 8.2 & 10.1 & 12.2 & 7.6 \\
\hline U2 & www.lpu.in & 50.4 & 7.9 & 6.8 & 7.1 & 14.9 & 6.5 \\
\hline U3 & www.punjabiuniversity.ac.in & 121.2 & -3.4 & 0.4 & 1.8 & -16.1 & -20.9 \\
\hline U4 & www.thapar.edu & 24.3 & 10.9 & 7.4 & 6.9 & 19.2 & 8.7 \\
\hline U5 & www.cup.ac.in & 121.2 & -3.4 & 0.4 & 1.8 & -16.1 & -20.9 \\
\hline U6 & www.sliet.ac.in & 37.6 & 8.8 & 4.3 & 5.8 & 16.3 & 5.9 \\
\hline U7 & www.davuniversity.org & 44 & 7.9 & 5.6 & 5.7 & 13.1 & 3.4 \\
\hline U8 & www.pau.edu & 45.9 & 8.3 & 3.8 & 6.9 & 12.3 & 3.9 \\
\hline U9 & www.iitrpr.ac.in & 15.6 & 12 & 6.9 & 6.6 & 21 & 9.8 \\
\hline U10 & www.puchd.ac.in & 40.8 & 8.9 & 5.9 & 6.9 & 14.3 & 5.3 \\
\hline U11 & www.bfuhs.ac.in & 18.4 & 15.4 & 7.6 & 11.6 & 20.5 & 17.1 \\
\hline U12 & www.gadvasu.in & 42 & 9 & 5.3 & 7.9 & 14.3 & 5.9 \\
\hline U13 & www.pec.ac.in & 15.6 & 12.2 & 6.4 & 7.2 & 21.6 & 10.8 \\
\hline U14 & www.ctuniversity.in & 50.4 & 7.5 & 6.2 & 6.4 & 15 & 5.8 \\
\hline U15 & www.gurukashiuniversity.in & 77.9 & 2.9 & 0.8 & 1.8 & 6.1 & -2.8 \\
\hline U16 & www.auts.ac.in & 41.9 & 8.1 & 6.9 & 5.4 & 15.4 & 5 \\
\hline U17 & www.gnauniversity.edu.in & 38.3 & 9.4 & 7.7 & 7.4 & 15.8 & 6.9 \\
\hline U18 & www.mrsphr.ac.in & 33.4 & 12.3 & 8.4 & 11.5 & 14.8 & 10.5 \\
\hline U19 & www.chitkara.edu.in & 34.2 & 9.7 & 5.7 & 7 & 16.2 & 6.6 \\
\hline U20 & www.rimt.ac.in & 35.7 & 9.9 & 8.4 & 7.8 & 17.2 & 8.3 \\
\hline U21 & www.rayatbahra.edu.in & 36.5 & 9.1 & 7.6 & 5.9 & 16.9 & 6.6 \\
\hline U22 & www.iimamritsar.ac.in & 49.2 & 7.8 & 5.1 & 7 & 13.3 & 4.6 \\
\hline U23 & www.adeshuniversity.ac.in & 22.2 & 10.8 & 3.8 & 5.5 & 21.1 & 9.5 \\
\hline U24 & www.web.gndu.ac.in & 41.8 & 8.6 & 5.9 & 6.3 & 15.5 & 6 \\
\hline & & & & & & \\
\hline
\end{tabular}

${ }^{x}$ means regional fonts are used in website 
Table A2:Text Statistics(30/09/2017)

\begin{tabular}{|llllllll|} 
S.No. & URLs & $\begin{array}{l}\text { No. of } \\
\text { sentences }\end{array}$ & $\begin{array}{l}\text { No. of } \\
\text { words }\end{array}$ & $\begin{array}{l}\text { No. of } \\
\text { complex } \\
\text { words }\end{array}$ & $\begin{array}{l}\text { \% of } \\
\text { complex } \\
\text { words }\end{array}$ & $\begin{array}{l}\text { Average } \\
\text { words/sen } \\
\text { tences }\end{array}$ & $\begin{array}{l}\text { Average } \\
\text { syllables/w } \\
\text { ords }\end{array}$ \\
\hline U1 & www.ptu.ac.in & 92 & 949 & 200 & 21.07 & 13.17 & 1.79 \\
\hline U2 & www.lpu.in & 538 & 2974 & 568 & 19.10 & 6.80 & 1.74 \\
\hline U3 & www.punjabiuniversity.ac.in & 1 & 1 & 0 & 0 & 1 & 1 \\
\hline U4 & www.thapar.edu & 193 & 683 & 166 & 24.30 & 4.28 & 1.96 \\
\hline U5 ${ }^{\mathbf{x}}$ & www.cup.ac.in & 1 & 1 & 0 & 0 & 1 & 1 \\
\hline U6 & www.sliet.ac.in & 161 & 451 & 114 & 25.28 & 3.17 & 1.90 \\
\hline U7 & www.davuniversity.org & 324 & 1056 & 278 & 26.3 & 3.31 & 1.88 \\
\hline U8 & www.pau.edu & 189 & 981 & 220 & 22.43 & 5.69 & 1.80 \\
\hline U9 & www.iitrpr.ac.in & 105 & 359 & 124 & 34.54 & 3.49 & 2.22 \\
\hline U10 & www.puchd.ac.in & 100 & 522 & 129 & 24.71 & 5.40 & 1.89 \\
\hline U11 & www.bfuhs.ac.in & 1 & 19 & 4 & 21.05 & 19 & 2 \\
\hline U12 & www.gadvasu.in & 381 & 2156 & 529 & 24.54 & 6.36 & 1.81 \\
\hline U13 & www.pec.ac.in & 148 & 602 & 190 & 31.56 & 4.47 & 2.17 \\
\hline U14 & www.ctuniversity.in & 135 & 700 & 154 & 22 & 5.19 & 1.79 \\
\hline U15 & www.gurukashiuniversity.in & 2 & 4 & 0 & 0 & 2.0 & 1.50 \\
\hline U16 & www.auts.ac.in & 453 & 1043 & 226 & 21.67 & 2.80 & 1.84 \\
\hline U17 & www.gnauniversity.edu.in & 335 & 1721 & 432 & 25.10 & 6.00 & 1.91 \\
\hline U18 & www.mrsphr.ac.in & 206 & 2976 & 789 & 26.51 & 14.92 & 1.87 \\
\hline U19 & www.chitkara.edu.in & 627 & 2381 & 561 & 23.56 & 4.83 & 1.89 \\
\hline U20 & www.rimt.ac.in & 192 & 1220 & 326 & 26.72 & 6.49 & 1.94 \\
\hline U21 & www.rayatbahra.edu.in & 269 & 991 & 257 & 25.93 & 3.68 & 1.97 \\
\hline U22 & www.iimamritsar.ac.in & 60 & 331 & 85 & 25.68 & 5.52 & 1.80 \\
\hline U23 & www.adeshuniversity.ac.in & 53 & 113 & 31 & 27.43 & 2.54 & 2.13 \\
\hline U24 & www.web.gndu.ac.in & 324 & 1487 & 364 & 24.48 & 4.61 & 1.89 \\
\hline
\end{tabular}

${ }^{\mathrm{x}}$ means regional fonts are used in website

Table A3: Average Grade Level Test Results (30/09/2017)

\begin{tabular}{|c|c|c|c|}
\hline S.No. & URLs & Average Grade Level & $\begin{array}{l}\text { No. of Years old to easily } \\
\text { understand }\end{array}$ \\
\hline U1 & www.ptu.ac.in & 10 & 15 to 16 \\
\hline U2 & www.lpu.in & 9 & 14 to 15 \\
\hline $\mathrm{U3}^{*}$ & www.punjabiuniversity.ac.in & -8 & -3 to -2 \\
\hline U4 & www.thapar.edu & 11 & 16 to 17 \\
\hline $\mathrm{U}^{*}{ }^{*}$ & www.cup.ac.in & -8 & -3 to -2 \\
\hline U6 & www.sliet.ac.in & 8 & 13 to 14 \\
\hline U7 & www.davuniversity.org & 7 & 12 to 13 \\
\hline U8 & www.pau.edu & 7 & 12 to 13 \\
\hline U9 & www.iitrpr.ac.in & 11 & 16 to 17 \\
\hline U10 & www.puchd.ac.in & 8 & 13 to 14 \\
\hline $\mathrm{U}_{11}{ }^{*}$ & www.bfuhs.ac.in & 14 & 19 to20 \\
\hline U12 & $\overline{\text { www.gadvasu.in }}$ & 8 & 13 to 14 \\
\hline U13 & www.pec.ac.in & 12 & 16 to 17 \\
\hline U14 & www.ctuniversity.in & 8 & 13 to 14 \\
\hline $\mathrm{U} 5^{*}$ & www.gurukashiuniversity.in & 2 & 07 to 08 \\
\hline U16 & www.auts.ac.in & 8 & 13 to 14 \\
\hline U17 & www.gnauniversity.edu.in & 9 & 14 to 15 \\
\hline U18 & www.mrsphr.ac.in & 12 & 17 to 18 \\
\hline U19 & www.chitkara.edu.in & 9 & 14 to 15 \\
\hline U20 & www.rimt.ac.in & 10 & 15 to 16 \\
\hline U21 & www.rayatbahra.edu.in & 9 & 14 to 15 \\
\hline U22 & www.iimamritsar.ac.in & 8 & 13 to 14 \\
\hline U23 & www.adeshuniversity.ac.in & 10 & 15 to 16 \\
\hline U24 & www.web.gndu.ac.in & 8 & 13 to 14 \\
\hline
\end{tabular}


Table B1:Readability Indices(30/10/2017)

\begin{tabular}{|llcccccc|}
\hline S.No. & \multicolumn{1}{c}{ URLs } & FKR & FKG & GF & SMOG & CL & AR \\
\hline U1 & www.ptu.ac.in & 39.3 & 11 & 8.2 & 10.1 & 12.2 & 7.5 \\
\hline U2 & www.lpu.in & 50.4 & 7.9 & 6.8 & 7.1 & 14.9 & 6.5 \\
\hline U3 & www.punjabiuniversity.ac.in & 121.2 & -3.4 & 0.4 & 1.8 & -16.1 & -20.9 \\
\hline U4 & www.thapar.edu & 25.5 & 10.8 & 7.3 & 6.9 & 18.9 & 8.5 \\
\hline U5 & www.cup.ac.in & 121.2 & -3.4 & 0.4 & 1.8 & -16.1 & -20.9 \\
\hline U6 & www.sliet.ac.in & 37.6 & 8.8 & 4.3 & 5.8 & 16.3 & 5.9 \\
\hline U7 & www.davuniversity.org & 44 & 7.9 & 5.6 & 5.7 & 13.1 & 3.4 \\
\hline U8 & www.pau.edu & 46.4 & 8.1 & 3.7 & 6.8 & 12.2 & 3.8 \\
\hline U9 & www.iitrpr.ac.in & 15.6 & 12 & 6.9 & 6.6 & 21 & 9.8 \\
\hline U10 & www.puchd.ac.in & 40.3 & 9 & 6 & 6.9 & 14.4 & 5.5 \\
\hline U11 & www.bfuhs.ac.in & 18.4 & 15.4 & 7.6 & 11.6 & 20.5 & 17.1 \\
\hline U12 & www.gadvasu.in & 43.7 & 8.7 & 5.3 & 7.8 & 13.9 & 5.5 \\
\hline U13 & www.pec.ac.in & 15.9 & 12.2 & 6.3 & 7.3 & 21.5 & 10.7 \\
\hline U14 & www.ctuniversity.in & 50.4 & 7.5 & 6.2 & 6.4 & 15 & 5.8 \\
\hline U15 & www.gurukashiuniversity.in & 77.9 & 2.9 & 0.8 & 1.8 & 6.1 & -2.8 \\
\hline U16 & www.auts.ac.in & 41.9 & 8.1 & 6.9 & 5.4 & 15.4 & 5 \\
\hline U17 & www.gnauniversity.edu.in & 40.2 & 9.1 & 7.7 & 7.3 & 15.6 & 6.7 \\
\hline U18 & www.mrsphr.ac.in & 33.1 & 12.4 & 8.5 & 11.6 & 14.9 & 10.7 \\
\hline U19 & www.chitkara.edu.in & 34.5 & 9.7 & 5.8 & 7 & 16.1 & 6.6 \\
\hline U20 & www.rimt.ac.in & 35.7 & 9.9 & 8.4 & 7.8 & 17.2 & 8.3 \\
\hline U21 & www.rayatbahra.edu.in & 37.2 & 9 & 7.4 & 5.8 & 16.6 & 6.3 \\
\hline U22 & www.iimamritsar.ac.in & 49.2 & 7.8 & 5.1 & 7 & 13.3 & 4.6 \\
\hline U23 & www.adeshuniversity.ac.in & 22.2 & 10.8 & 3.8 & 5.5 & 21.1 & 9.5 \\
\hline U24 & www.web.gndu.ac.in & 42.1 & 8.6 & 6.1 & 6.5 & 15.4 & 6 \\
\hline
\end{tabular}

${ }^{x}$ means regional fonts are used in website

Table B2:Text Statistics(30/10/2017)

\begin{tabular}{|llllllll|} 
S.No. & URLs & $\begin{array}{l}\text { No. of } \\
\text { sentences }\end{array}$ & $\begin{array}{l}\text { No. of } \\
\text { words }\end{array}$ & $\begin{array}{l}\text { No. of } \\
\text { complex } \\
\text { words }\end{array}$ & $\begin{array}{l}\text { \% of } \\
\text { complex } \\
\text { words }\end{array}$ & $\begin{array}{l}\text { Average } \\
\text { words/sen } \\
\text { tences }\end{array}$ & $\begin{array}{l}\text { Average } \\
\text { syllables/w } \\
\text { ords }\end{array}$ \\
\hline U1 & www.ptu.ac.in & 92 & 940 & 198 & 21.06 & 13.04 & 1.79 \\
\hline U2 & www.lpu.in & 538 & 2974 & 568 & 19.10 & 6.80 & 1.74 \\
\hline U3 & www.punjabiuniversity.ac.in & 1 & 1 & 0 & 0 & 1 & 1 \\
\hline U4 & www.thapar.edu & 196 & 692 & 165 & 23.84 & 4.27 & 1.94 \\
\hline U5 & www.cup.ac.in & 1 & 1 & 0 & 0 & 1 & 1 \\
\hline U6 & www.sliet.ac.in & 161 & 451 & 114 & 25.28 & 3.17 & 1.90 \\
\hline U7 & www.davuniversity.org & 324 & 1056 & 278 & 26.3 & 3.31 & 1.88 \\
\hline U8 & www.pau.edu & 189 & 945 & 214 & 22.65 & 5.48 & 1.80 \\
\hline U9 & www.iitrpr.ac.in & 105 & 359 & 124 & 34.54 & 3.49 & 2.22 \\
\hline U10 & www.puchd.ac.in & 101 & 522 & 129 & 24.71 & 5.40 & 1.89 \\
\hline U11 & www.bfuhs.ac.in & 1 & 19 & 4 & 21.05 & 19 & 2 \\
\hline U12 & www.gadvasu.in & 381 & 2156 & 529 & 24.54 & 6.36 & 1.81 \\
\hline U13 & www.pec.ac.in & 148 & 602 & 190 & 31.56 & 4.47 & 2.17 \\
\hline U14 & www.ctuniversity.in & 135 & 700 & 154 & 22 & 5.19 & 1.79 \\
\hline U15 & www.gurukashiuniversity.in & 2 & 4 & 0 & 0 & 2.0 & 1.50 \\
\hline U16 & www.auts.ac.in & 453 & 1043 & 226 & 21.67 & 2.80 & 1.84 \\
\hline U17 & www.gnauniversity.edu.in & 335 & 1721 & 419 & 24.35 & 6.00 & 1.89 \\
\hline U18 & www.mrsphr.ac.in & 206 & 3029 & 800 & 26.41 & 15.19 & 1.87 \\
\hline U19 & www.chitkara.edu.in & 632 & 2405 & 566 & 23.53 & 4.84 & 1.89 \\
\hline U20 & www.rimt.ac.in & 192 & 1220 & 326 & 26.72 & 6.49 & 1.94 \\
\hline U21 & www.rayatbahra.edu.in & 278 & 998 & 257 & 25.75 & 3.59 & 1.96 \\
\hline U22 & www.iimamritsar.ac.in & 60 & 331 & 85 & 25.68 & 5.52 & 1.80 \\
\hline U23 & www.adeshuniversity.ac.in & 53 & 113 & 31 & 27.43 & 2.54 & 2.13 \\
\hline U24 & www.web.gndu.ac.in & 331 & 1596 & 391 & 24.5 & 4.84 & 1.89 \\
\hline
\end{tabular}

${ }^{x}$ means regional fonts are used in website 
Table B3: Average Grade Level Test Results (30/10/2017)

\begin{tabular}{|c|c|c|c|}
\hline S.No. & URLs & Average Grade Level & $\begin{array}{l}\text { No. of Years old to easily } \\
\text { understand }\end{array}$ \\
\hline U1 & www.ptu.ac.in & 10 & 15 to 16 \\
\hline $\mathbf{U} 2$ & www.lpu.in & 9 & 14 to 15 \\
\hline $\mathbf{U 3}^{*}$ & www.punjabiuniversity.ac.in & -8 & -3 to -2 \\
\hline U4 & www.thapar.edu & 10 & 15 to 16 \\
\hline $\mathrm{U5}^{*}$ & www.cup.ac.in & -8 & -3 to -2 \\
\hline U6 & www.sliet.ac.in & 8 & 13 to 14 \\
\hline U7 & www.davuniversity.org & 7 & 12 to 13 \\
\hline U8 & www.pau.edu & 7 & 12 to 13 \\
\hline U9 & www.iitrpr.ac.in & 11 & 16 to 17 \\
\hline U10 & www.puchd.ac.in & 8 & 13 to 14 \\
\hline $\mathrm{U11}^{*}$ & www.bfuhs.ac.in & 14 & 19 to 20 \\
\hline U12 & www.gadvasu.in & 8 & 13 to 14 \\
\hline U13 & www.pec.ac.in & 12 & 16 to 17 \\
\hline U14 & www.ctuniversity.in & 8 & 13 to 14 \\
\hline U15 ${ }^{*}$ & www.gurukashiuniversity.in & 2 & 07 to 08 \\
\hline U16 & www.auts.ac.in & 8 & 13 to 14 \\
\hline U17 & www.gnauniversity.edu.in & 9 & 14 to 15 \\
\hline U18 & www.mrsphr.ac.in & 12 & 17 to 18 \\
\hline U19 & www.chitkara.edu.in & 9 & 14 to 15 \\
\hline U20 & www.rimt.ac.in & 10 & 15 to 16 \\
\hline U21 & www.rayatbahra.edu.in & 9 & 14 to 15 \\
\hline U22 & www.iimamritsar.ac.in & 8 & 13 to 14 \\
\hline $\mathrm{U} 23$ & www.adeshuniversity.ac.in & 10 & 15 to 16 \\
\hline U24 & www.web.gndu.ac.in & 8 & 13 to 14 \\
\hline
\end{tabular}

\section{${ }^{x}$ means regional fonts are used in website}

Table C1:Readability Indices(30/11/17)

\begin{tabular}{|llcccccc|}
\hline S.No. & \multicolumn{1}{c}{ URLs } & FKR & FKG & GF & SMOG & CL & AR \\
\hline U1 & www.ptu.ac.in & 39.3 & 11 & 8.2 & 10.1 & 12.2 & 7.5 \\
\hline U2 & www.lpu.in & 50.4 & 7.9 & 6.8 & 7.1 & 14.9 & 6.5 \\
\hline U3 & www.punjabiuniversity.ac.in & 121.2 & -3.4 & 0.4 & 1.8 & -16.1 & -20.9 \\
\hline U4 & www.thapar.edu & 25.5 & 10.8 & 7.3 & 6.9 & 18.9 & 8.5 \\
\hline U5 & www.cup.ac.in & 121.2 & -3.4 & 0.4 & 1.8 & -16.1 & -20.9 \\
\hline U6 & www.sliet.ac.in & 37.6 & 8.8 & 4.3 & 5.8 & 16.3 & 5.9 \\
\hline U7 & www.davuniversity.org & 44.9 & 7.8 & 5.6 & 5.6 & 12.9 & 3.2 \\
\hline U8 & www.pau.edu & 48 & 7.9 & 3.6 & 6.7 & 11.4 & 3.1 \\
\hline U9 & www.iitrpr.ac.in & 16.6 & 11.9 & 8 & 6.9 & 20.6 & 9.7 \\
\hline U10 & www.puchd.ac.in & 40.3 & 9 & 6 & 6.9 & 14.4 & 5.5 \\
\hline U11 & www.bfuhs.ac.in & 18.4 & 15.4 & 7.6 & 11.6 & 20.5 & 17.1 \\
\hline U12 & www.gadvasu.in & 43.6 & 8.7 & 5.4 & 7.8 & 14.1 & 5.6 \\
\hline U13 & www.pec.ac.in & 15.9 & 12.2 & 6.3 & 7.3 & 21.5 & 10.7 \\
\hline U14 & www.ctuniversity.in & 50.4 & 7.5 & 6.2 & 6.4 & 15 & 5.8 \\
\hline U15 & www.gurukashiuniversity.in & 77.9 & 2.9 & 0.8 & 1.8 & 6.1 & -2.8 \\
\hline U16 & www.auts.ac.in & 41.9 & 8.1 & 6.9 & 5.4 & 15.4 & 5 \\
\hline U17 & www.gnauniversity.edu.in & 38.5 & 9.3 & 7.6 & 7.3 & 15.8 & 6.8 \\
\hline U18 & www.mrsphr.ac.in & 32.6 & 12.5 & 8.5 & 11.7 & 14.9 & 10.8 \\
\hline U19 & www.chitkara.edu.in & 34.5 & 9.7 & 5.8 & 7 & 16.1 & 6.6 \\
\hline U20 & www.rimt.ac.in & 35.7 & 9.9 & 8.4 & 7.8 & 17.2 & 8.3 \\
\hline U21 & www.rayatbahra.edu.in & 37 & 9 & 7.4 & 5.8 & 16.6 & 6.4 \\
\hline U22 & www.iimamritsar.ac.in & 49.2 & 7.8 & 5.1 & 7 & 13.3 & 4.6 \\
\hline U23 & www.adeshuniversity.ac.in & 22.2 & 10.8 & 3.8 & 5.5 & 21.1 & 9.5 \\
\hline U24 & www.web.gndu.ac.in & 41 & 8.78 & 6.2 & 6.5 & 15.7 & 6.2 \\
\hline
\end{tabular}


Table C2: Text Statistics(30/11/17)

\begin{tabular}{|llllllll|} 
S.No. & URLs & $\begin{array}{l}\text { No. of } \\
\text { sentences }\end{array}$ & $\begin{array}{l}\text { No. of } \\
\text { words }\end{array}$ & $\begin{array}{l}\text { No. of } \\
\text { complex } \\
\text { words }\end{array}$ & $\begin{array}{l}\text { \% of } \\
\text { complex } \\
\text { words }\end{array}$ & $\begin{array}{l}\text { Average } \\
\text { words/sen } \\
\text { tences }\end{array}$ & $\begin{array}{l}\text { Average } \\
\text { syllables/w } \\
\text { ords }\end{array}$ \\
\hline U1 & www.ptu.ac.in & 92 & 940 & 198 & 21.06 & 13.04 & 1.79 \\
\hline U2 & www.lpu.in & 538 & 2974 & 568 & 19.10 & 6.80 & 1.74 \\
\hline U3 $^{\mathbf{x}}$ & www.punjabiuniversity.ac.in & 1 & 1 & 0 & 0 & 1 & 1 \\
\hline U4 & www.thapar.edu & 196 & 689 & 165 & 23.95 & 4.24 & 1.94 \\
\hline U5 $^{\mathbf{x}}$ & www.cup.ac.in & 1 & 1 & 0 & 0 & 1 & 1 \\
\hline U6 & www.sliet.ac.in & 161 & 451 & 114 & 25.28 & 3.17 & 1.90 \\
\hline U7 & www.davuniversity.org & 320 & 1038 & 272 & 26.20 & 3.29 & 1.87 \\
\hline U8 & www.pau.edu & 194 & 970 & 214 & 22.06 & 5.46 & 1.78 \\
\hline U9 & www.iitrpr.ac.in & 108 & 414 & 141 & 34.06 & 3.91 & 2.20 \\
\hline U10 & www.puchd.ac.in & 101 & 527 & 131 & 24.86 & 5.39 & 1.89 \\
\hline U11 & www.bfuhs.ac.in & 1 & 19 & 4 & 21.05 & 19 & 2 \\
\hline U12 & www.gadvasu.in & 390 & 2176 & 538 & 24.72 & 6.27 & 1.79 \\
\hline U13 & www.pec.ac.in & 148 & 602 & 190 & 31.56 & 4.47 & 2.17 \\
\hline U14 & www.ctuniversity.in & 135 & 700 & 154 & 22 & 5.19 & 1.79 \\
\hline U15 & www.gurukashiuniversity.in & 2 & 4 & 0 & 0 & 2.0 & 1.50 \\
\hline U16 & www.auts.ac.in & 453 & 1043 & 226 & 21.67 & 2.80 & 1.84 \\
\hline U17 & www.gnauniversity.edu.in & 339 & 1714 & 428 & 24.97 & 5.89 & 1.91 \\
\hline U18 & www.mrsphr.ac.in & 202 & 3003 & 795 & 26.47 & 15.36 & 1.87 \\
\hline U19 & www.chitkara.edu.in & 632 & 2405 & 566 & 23.53 & 4.84 & 1.89 \\
\hline U20 & www.rimt.ac.in & 192 & 1220 & 326 & 26.72 & 6.49 & 1.94 \\
\hline U21 & www.rayatbahra.edu.in & 278 & 998 & 258 & 25.85 & 3.59 & 1.96 \\
\hline U22 & www.iimamritsar.ac.in & 60 & 331 & 85 & 25.68 & 5.52 & 1.80 \\
\hline U23 & www.adeshuniversity.ac.in & 53 & 113 & 31 & 27.43 & 2.54 & 2.13 \\
\hline U24 & www.web.gndu.ac.in & 314 & 1473 & 374 & 25.39 & 4.71 & 1.90 \\
\hline
\end{tabular}

${ }^{\mathrm{x}}$ means regional fonts are used in website

Table C3:Average Grade(30/11/17)

\begin{tabular}{|c|c|c|c|}
\hline S.No. & URLs & Average Grade Level & $\begin{array}{l}\text { No. of Years old to easily } \\
\text { understand }\end{array}$ \\
\hline U1 & www.ptu.ac.in & 10 & 15 to 16 \\
\hline U2 & www.lpu.in & 9 & 14 to 15 \\
\hline $\mathbf{U 3}^{\mathrm{x}}$ & www.punjabiuniversity.ac.in & -8 & -3 to -2 \\
\hline U4 & www.thapar.edu & 10 & 15 to 16 \\
\hline $\mathrm{U}^{\mathrm{x}}$ & www.cup.ac.in & -8 & -3 to -2 \\
\hline U6 & www.sliet.ac.in & 8 & 13 to 14 \\
\hline U7 & www.davuniversity.org & 7 & 12 to 13 \\
\hline U8 & www.pau.edu & 7 & 12 to 13 \\
\hline U9 & www.iitrpr.ac.in & 11 & 16 to 17 \\
\hline U10 & www.puchd.ac.in & 8 & 13 to 14 \\
\hline $\mathrm{U}_{11}{ }^{\mathrm{x}}$ & www.bfuhs.ac.in & 14 & 19 to 20 \\
\hline U12 & $\overline{\text { www.gadvasu.in }}$ & 8 & 13 to 14 \\
\hline U13 & www.pec.ac.in & 12 & 16 to 17 \\
\hline U14 & www.ctuniversity.in & 8 & 13 to 14 \\
\hline $\mathrm{U}^{1} 5^{\mathrm{x}}$ & www.gurukashiuniversity.in & 2 & 07 to 08 \\
\hline U16 & www.auts.ac.in & 8 & 13 to 14 \\
\hline U17 & www.gnauniversity.edu.in & 9 & 14 to 15 \\
\hline U18 & www.mrsphr.ac.in & 12 & 17 to 18 \\
\hline U19 & www.chitkara.edu.in & 9 & 14 to 15 \\
\hline U20 & www.rimt.ac.in & 10 & 15 to 16 \\
\hline U21 & www.rayatbahra.edu.in & 9 & 14 to 15 \\
\hline U22 & www.iimamritsar.ac.in & 8 & 13 to 14 \\
\hline U23 & www.adeshuniversity.ac.in & 10 & 15 to 16 \\
\hline U24 & www.web.gndu.ac.in & 9 & 14 to 15 \\
\hline
\end{tabular}

